\title{
Knowledge, Practice and Challenges of Exclusive Breastfeeding among working mothers attending antenatal clinic in Lagos University Teaching Hospital, Idiaraba
}

\author{
Ogunmodi Oluwatosin Adebayo (RN, RM, BNSc) \\ Department of Nursing Science, University of Jos. \\ Plateau state, Nigeria. \\ charistosin@gmail.com \\ Co-authors: \\ Daniel Grace Omolade (RN, RM, BNSc, MSc) \\ Department of Nursing Science, University of Jos. \\ Plateau state, Nigeria. \\ gracemola2002@yahoo.co.uk \\ Ajala Cecelia Kehinde \\ Deputy Director of Nursing Service \\ Lagos University Teaching Hospital, Idi-araba, \\ Lagos state, Nigeria. \\ kehindeajala4@gmail.com
}
Shittu Fatimah Folashade (RN, RM, BSc, PGD)
Lagos University Teaching Hospital, Idi-araba,
Lagos state, Nigeria.
fatshade2001@yahoo.com
Nnademere Christian Chiemeka (RN, RM, BNSc)
Lagos University Teaching Hospital, Idi-araba,
Lagos state, Nigeria.
nnademere.christian@gmail.com

DOI: $10.31364 /$ SCIRJ/v8.i2.2020.P0220744

http://dx.doi.org/10.31364/SCIRJ/v8.i2.2020.P0220744

\begin{abstract}
The World Health Organization (WHO) recommends exclusive breastfeeding for the first six months of life and continuation of breastfeeding and adequate complementary foods for up to two years of age or beyond. The objective of this study was to assess the knowledge, practice and challenges of exclusive breastfeeding among working mothers attending antenatal clinic in Lagos University Teaching Hospital, Idi-araba. Using a descriptive research design and a self structured questionnaire, data was collected from 189 respondents, presented in frequency tables, interpreted and analysed using the statistical production for service solution (SPSS) version 20. Result showed that more than half of the respondents (53.4\%) are within the age range 33-37 years and a majority $(94.7 \%)$ were married, most $(68.8 \%)$ practice Christianity, majority $(62.4 \%)$ had the secondary level of educational qualification, more than half $(59.8 \%)$ were self employed with almost half (49.7\%) earning an average income status. In this study, majority of the respondents (62.4\%) have good knowledge on exclusive breastfeeding and most (63\%) got their information from the hospital, likewise majority (59.8\%) have good practice of breastfeeding. The most challenging factors of exclusive breastfeeding identify in this study were: health condition of the mother (58.7\%), health condition of the baby $(52.4 \%)$, cracked or sore nipples $(39.2 \%)$, inadequate production of milk $(36.9 \%)$ and work schedule $(30.2 \%)$. there is a significant relationship between knowledge of
\end{abstract}


exclusive breastfeeding and its practice among working mothers attending antenatal clinic in Lagos University Teaching Hospital, Idiaraba. Similarly there is a significant relationship between practice of exclusive breastfeeding and respondents' educational qualification. In conclusion the practice of EBF is influenced by its' knowledge and also educational qualification of respondents. Health condition of mother and baby as well as cracked or sore nipples also hindered the practice of EBF. It is therefore recommended that Health sector should mandate that proper health education is carried out in hospitals for pregnant women receiving antenatal care in their facilities and Nurrses/Midwives should encourage and ensure post partum care is adequately given to both the mother and baby.

Keywords: Knowledge, Practice, Challenges, Exclusive Breastfeeding, Working mothers

\section{CHAPTER ONE}

\section{INTRODUCTION}

\subsection{BACKGROUND OF STUDY}

Breast milk is considered as the most complete nutritional source for infants because it contains the essential fats, carbohydrates, proteins, and immunological factors needed for infants to thrive and resist infection in the formative first year of life [1][2][3]. Based on this, the World Health Organization (WHO) recommends exclusive breastfeeding for the first six months of life and continuation

of breastfeeding and adequate complementary foods for up to two years of age or beyond [4]. Exclusive breastfeeding (EBF) is defined as exclusive intake of breast milk by an infant from its mother or wet nurse or expressed milk with addition of no other liquid or solid with the exception of drops or syrups consisting of vitamins, minerals supplements, or medicine and nothing else for the first six months [4].

Over the last couple of decades, there has been an increasing interest in the promotion of exclusive breastfeeding as the 'best' feeding method for newborns. This, to a large extent, has been inspired by mounting scientific evidence on the importance of exclusive breastfeeding in reducing infant morbidity and mortality. In resource limited settings where poor and sub- optimal breastfeeding practices frequently result to child malnutrition which is a major cause of more than half of all child deaths, exclusive breastfeeding is regarded as imperative for infants' survival. Indeed, of the 6.9 million under five children who were reported dead globally in 2011 [5], an estimated 1 million lives could have been saved by simple and accessible practices such as exclusive breastfeeding. Consequently, the WHO and UNICEF have recommended exclusive breastfeeding for six months, followed by introduction of complementary foods and continued breastfeeding for 24 months or more [5].

Breastfeeding has many health benefits for both mother and infant. Breast milk contains all the necessary nutrients the infant needs in the first six months of life. Breastfeeding protects against diarrhea and common childhood illnesses such as pneumonia and may also have long term benefits for the mother and child, such as reducing the risk of obesity in childhood and adolescence [6]. The advantages include a lower risk of gastrointestinal infections for the baby, more rapid recuperation after birth and delayed return of 
menstrual periods (a natural method of family planning). Breastfeeding also provides infants with superior nutritional content that is capable of improving the immunity and possible reduction of future health care spending [7].

EBF for six months is important for both infant and maternal health. Infants who are not exclusively breastfeeding are more likely to develop gastrointestinal infections, not only in developing but also in industrialized countries [8]. The risk of mortality due to diarrhea and other infections can increase many-fold in infants who are either partially breastfed or not breastfed at all [8]. During the first two months of life, infants who are not breastfed are nearly six times more likely to die from infectious diseases than infants who are breastfed; between 2 and 3 months, non-breastfed infants are 4 times more likely to die compared to breastfed infants [8].

There are many benefits of practicing breastfeeding but it has been shown that there are barriers to the optimal practice of breastfeeding. Some of these barriers include hospital practices, advertisement of breast mill substitutes and lack of support for the breastfeeding mother. Many women identify their employment as a barrier to optimal breastfeeding [7].

It is almost certain that women who return to work before their babies are six months old will face challenges in adhering to the practice of EBF.

The researcher is motivated to carry out this study due to the challenges observed that may be incurred by working mothers who intend to practice EBF.

\subsection{STATEMENT OF PROBLEM}

In Nigeria, breastfeeding is universal with almost all babies being breastfed but the practice of EBF is rare with only $17 \%$ of children younger than six months being exclusively breastfed [9]. This has led to an increased incidence of morbidity from infectious diseases, including otitis media, gastroenteritis, and pneumonia, as well as elevated risks of childhood obesity, type 1 and type 2 diabetes, leukemia and sudden infant death syndrome [10]. The benefits of exclusive breastfeeding for both mother and child are universally acknowledged by health providers, global health agencies and lay people [11].

Many attempts to promote EBF have achieved less than the desired outcomes and in order to comprehend the dynamics of this practice, a number of studies have been conducted in Nigeria and in many parts of the world [11]. Much of these studies have focused on knowledge and attitude of EBF, health outcomes of exclusive and nonexclusive breastfeeding and prospective positions of husbands in breastfeeding decisions. Much less attempts however, have been made at examining the factors affecting the practice of EBF among nursing mothers. This research therefore seeks to assess knowledge, practices and challenges of exclusive breastfeeding among working mothers attending antenatal clinic in Lagos University Teaching Hospital, Idi-araba. 


\subsection{OBJECTIVE OF THE STUDY}

The broad objective of this study is to assess the knowledge, practice and challenges of exclusive breastfeeding among working mothers attending antenatal clinic in Lagos University Teaching Hospital, Idi-araba.

The specific objectives are to:

i. Assess the knowledge of exclusive breastfeeding among working mothers attending antenatal clinic in Lagos University Teaching Hospital, Idi-araba.

ii. Assess the practice of exclusive breastfeeding among working mothers attending antenatal clinic in Lagos University Teaching Hospital, Idi-araba.

iii. Assess the challenges of exclusive breastfeeding among working mothers attending antenatal clinic in Lagos University Teaching Hospital, Idi-araba.

\subsection{SIGNIFICANCE OF STUDY}

The findings of this study will help inform of the importance of breastfeeding to both mother and baby. It will also help inform mothers and the community at large on the effect the practice of non-exclusive breastfeeding will have on both mother and baby which will improve the overall practice of breastfeeding and also improve the child's well-being. The findings will further help the healthcare practitioners in creating policies that will enhance the practice of breastfeeding and also to identify the challenges of breastfeeding practice which in turn will promote educating the mothers on the best way to practice breastfeeding despite these factors. It will help to inform the policies targeted at behaviours among mothers that seek to enhance the practice of the exclusive breastfeeding in Nigeria.

\subsection{RESEARCH QUESTIONS}

i. Do the working mothers attending antenatal clinic in Lagos University Teaching Hospital, Idi-araba have adequate knowledge about exclusive breastfeeding?

ii. What percentage of working mothers attending antenatal clinic in Lagos University Teaching Hospital, Idi-araba practice exclusive breastfeeding?

iii. What are the challenges of exclusive breastfeeding among working mothers attending antenatal clinic in Lagos University Teaching Hospital, Idi-araba?

\subsection{RESEARCH HYPOTHESES}

WWW.scirj.org

(C) 2020, Scientific Research Journal

http://dx.doi.org/10.31364/SCIRJ/v8.i2.2020.P0220744 
$\mathrm{Ho}_{1}$ : There is no significant association between the knowledge of exclusive breastfeeding and its practice among working mothers attending antenatal clinic in Lagos University Teaching Hospital, Idi-araba.

$\mathrm{Ho}_{2}$ : There is no significant association between the practice of exclusive breastfeeding and the educational qualification of working mothers attending antenatal clinic in Lagos University Teaching Hospital, Idi-araba.

\subsection{SCOPE OF STUDY}

This study will be carried out among working mothers attending antenatal clinic in Lagos University Teaching Hospital, Idi-araba to assess the knowledge, practice and challenges of exclusive breastfeeding. Participants will be obtained from a random sampling of working mothers who attended antenatal visit within the study duration.

\subsection{OPERATIONAL DEFINITION OF TERMS}

Knowledge: This refers to the awareness of exclusive breastfeeding.

Practice: This is an act of carrying out or engaging in exclusive breastfeeding

Challenges: factors that may prevent the mother from carrying out exclusive breastfeeding effectively.

Exclusive Breastfeeding: It is an act of giving infant breast milk only for the first six months of life, introducing complementary feeds after six months though breastfeeding continues till two years of life.

Working mothers: These imply women who are engaged in a business or work and have under-five children and attends antenatal clinic in Lagos University Teaching Hospital, Idi-araba.

\section{CHAPTER TWO}

\subsection{HUMAN BREAST MILK}

Breast milk provides the ideal nutrients for infants. It has nearly the perfect mix of vitamins, proteins and fat, everything the baby needs to grow. It is provided in a more digestible form than formula feed. Breast milk contains antibodies that help the baby fight of bacteria and viruses. Breast feeding lowers the baby's risk for developing asthma or allergies [6]. It is ultimately the best source of nutrition for a new born baby. Many components in the breast milk help to protect the baby against infection and disease. The proteins 
in breast milk are more easily digestible than in formula and cow's milk. The calcium and iron in breast milk are also more easily absorbed [12]. The following are nutrients found in the human breast milk:

Proteins: the human milk contains two types of proteins: whey and casein in the proportion $60 \%$ and $40 \%$ respectively. This proportion allows for easy and quick digestion. Artificial milk or formula has a higher percentage of casein which is harder to digest [12].

Fats: these fats are necessary for brain development, absorption of fat-soluble vitamins and are a primary calorie source. Long chain fatty acids are needed for the brain, retina and nervous system. They are deposited in the brain during the last trimester of pregnancy and also found in human breast milk [12].

Vitamins: the amount and types of vitamins found in the breast milk is directly related to the mother's intake. This is why it is essential that the mother get adequate nutrition, including vitamins [12].

Carbohydrates: lactose is the primary carbohydrate found in human breast milk. It accounts for approximately $40 \%$ of the calories provided by the human breast milk. Lactose helps to decrease the amount of unhealthy bacteria in the stomach, which improves the absorption of calcium, phosphorus and magnesium. It helps to fight diseases and promotes the growth of healthy bacteria in the stomach [12].

\subsection{TYPES OF BREAST MILK}

The first stage of milk that develops during pregnancy is known as colostrum. Thick and yellow in color, colostrum lasts a few days after the baby is born. This milk is rich in protein, antibodies, vitamins and minerals [13]. Approximately two to four days after the baby is born, transitional milk replaces colostrum. Transitional milk is thin and white and contains high amount of fat, calories, proteins, lactose and vitamins. Many mothers notice the quantity and consistency of their milk changing about two to three days after their baby's birth [13]. Approximately 10-15 days following the baby's birth, the production of mature milk begins. Mature milk primarily consists of water and it often appears bluish in color at the beginning of feeding (foremilk) and turns white at the end of feeding (hind milk) as the milk's fat content increases. The consumption of hind milk is essential to ensure the baby is getting adequate nutrition [13].

A new-born's stomach is approximately the size of a marble and the baby's stomach walls cannot stretch. The amount of colostrum produced by the mother's breasts equals the amount the baby's stomach can hold. The baby's stomach increases roughly the size of a golf ball from seven to ten days [13]. 


\subsection{CONCEPT OF BREASTFEEDING}

For millennia, the word breastfeeding has meant feeding an infant at his/her own mother's breast. With the recent introduction of high efficiency breast pumps, other possibilities are now widely used, including feeding an infant his/her own mother's milk from a cup or bottle this milk may recently be pumped or stored for a short or long time [14]. According to Stoppler [15], breastfeeding is the process of feeding infant human breast milk. According to the American Academy of Pediatrics [16], human breast milk is preferred for all infants. This includes even premature and sick babies, with rare exceptions. It is the food least likely to cause allergic reactions; it is readily available at any hour of the day or night; babies accept the taste readily and the antibodies in the milk can help the baby resist infections.

Breastfeeding can begin within minutes after birth for most babies. Most babies take a few licks or sucks and then pause at the beginning. Frequent burst of sucking is interrupted by pauses is the usual pattern for the first few hours and sometimes even the first few days [15].

Breastfeeding has many health benefits for both mother and infant. Breast milk contains all the nutrients the infant needs in the first six months of life. Breastfeeding protects against diarrhea and common childhood illnesses such as pneumonia and may also have longer health benefits for the mother and child, such as reducing the risk of overweight and obesity in childhood and adolescence [6]. Breastfeeding has clear short-term benefits for child survival through reduction of morbidity and mortality from infectious diseases. Breastfeeding also has long-term benefits through an increase in intelligence quotient by 3.5 points at childhood and adolescence [17].

\subsection{PHYSIOLOGY OF BREASTFEEDING}

Once the alveolar epithelial cells have developed into lactocytes around mid-pregnancy, they are able to produce small quantities of secretion; colostrum. Although some women may produce as much as $30 \mathrm{ml}$ per day in late pregnancy, the production of milk is held in abeyance until 30-40 hours following the birth, when placental hormones have fallen sufficiently to allow the high levels of prolactin to initiate milk production. Continued production of prolactin is caused by touch as the baby feeds at the breast, with concentrations highest during the night feeds [18]. Prolactin is involved in suppression of ovulation and some women may remain anovular until lactation ceases. Prolactin seems to be more important to the initiation of lactation than to its continuation. As lactation progresses, the prolactin response to suckling diminishes and milk removal becomes the driving force behind milk production. This is known to be due to the presence in secreted milk of a whey protein that is able to inhibit the synthesis of milk constituents [18].

Milk is synthesized continuously into the alveolar lumen, where it is stored until milk removal from the breast in initiated. Only when oxytocin is released and the myoepithelial cells contract, is milk made available to the suckling baby. Milk release is under 
neuroendocrine control. Tactile stimulation of the breast also stimulates oxytocin, causing contraction of the myoepithelial cells. This process is known as let-down or milk-ejection reflex and makes the milk available to the baby. This occurs in discrete pulses throughout the feed and may trigger bursts of active feeding [18]. In the early days of lactation, the reflex is unconditioned. Later, as it becomes a conditioned reflex, the mother may find her breasts responding to the baby's cry or other circumstances associated with the baby or feeding [18].

\subsection{ADVANTAGES OF BREASTFEEDING TO THE MOTHER}

Weight loss: while some women tend to gain weight during breastfeeding, others tend to lose weight effortlessly lose weight. Although breastfeeding increases mothers' demands by about 500 calories per day, the body's hormonal balance is very different from normal. Because of these hormonal changes, lactating mothers have an increased appetite and may be more prone to storing fat for milk production. For the first three months after delivery, breastfeeding mothers may lose less weight than women who do not breastfeed and they may gain weight. However after three months of lactation, they will likely experience an increase in fat burning [19].

Contraction of the uterus: during pregnancy, the uterus grows immensely, expanding from the size of a pear to filling almost the entire space of the abdomen. After delivery, the uterus goes through a process called involution which helps to return it to its prepregnant size. Oxytocin helps in this process and its secretion increases during breastfeeding. It also encourages uterine contractions and reduces bleeding, helping the uterus return to its previous size [19].

Lower risk of depression: postpartum depression is a type of depression that can develop shortly after childbirth affecting up to $15 \%$ of mothers. Breastfeeding causes hormonal changes that encourage maternal care giving and bonding. Oxytocin production which increases during breastfeeding is thought to have long-term anti-anxiety specific brain regions that promote nurturing and relaxation. These effects may also partly explain why breastfeeding mothers have a lower rate of maternal neglect, compared to those who do not breastfeed [19].

Reduced disease risk: according to Bjarnadottir [19], breastfeeding seems to provide the mother with long-term protection against cancer and several diseases. The total time a woman spends breastfeeding is linked with a reduced risk of breast and ovarian cancer. Women who breastfeed for more than 12 months in their lifetime have a $28 \%$ lower risk for both breast and ovarian cancer. Each year of breastfeeding is associated with a $4.3 \%$ decrease in breast cancer risk. Women who breastfeed for 1-2 years over their lifetime have a 10-50\% lower risk of high blood pressure, arthritis, high blood fats, disease and type 2 diabetes. 
Prevention of Menstruation: continued breastfeeding also pauses ovulation and menstruation. The suspension of menstrual cycles may actually be nature's way of ensuring there is some time in between pregnancies [19]. This is referred to as Lactational amenorrhoea.

Saves time and money: breastfeeding is completely free and requires very little effort. By choosing breast feeding, there will not be a need to spend money on formula, spend time cleaning and sterilizing bottles, mix and warm up bottles in the middle of the night or day, figure out ways to warm up bottles while on the go [19].

\subsection{ADVANTAGES OF BREASTFEEDING TO THE BABY}

Protection against illness: several studies have shown that stomach viruses, lower respiratory problems, ear infections and meningitis are far less common in infants who are breastfed [20].

Protection against death: it is estimated that a breastfed child has a $20 \%$ less risk of dying between the ages of 28 days and one year, compared with a non-breastfed baby. According to the World Health Organization, if every child was breastfed within an hour of birth, given only breast milk for their first six months of life, and continued breastfeeding to the age of two years, an estimated 800,000 child lives could be saved every year [20].

Protection throughout childhood: protection against illness lasts way beyond the breastfeeding stage and studies have shown that breastfeeding can reduce a child's risk of developing certain childhood cancers, high cholesterol, inflammatory bowel disease, high blood pressure, Crohn's disease, ulcerative colitis and type 1 and type 2 diabetes [20].

Protection against allergies: babies who are fed a formula based on cow's milk or soy run a much higher risk of suffering allergic reactions once food is introduced. Breast milk has the ability to protect against disease and allergy due to a substance called Immunoglobulin A (igA). This substance guards against the invasion of germs by forming a protective layer on the mucous membranes in the baby's intestines, nose and throat. When exposed to bacteria, the baby's body responds to the pathogen by creating secretory IgA that's specific to the illness trying to break in [20].

Boosts intelligence: there is a strong link between breastfeeding and cognitive development and researchers have suggested that the longer the child is breastfed, the higher the IQ scores will be [20]. 
Helps control weight: studies have shown that a breastfed child is less likely to become obese as a teen or adult. The reason for this may be that a breastfed child learns to eat only their hunger is satisfied, setting a good eating pattern for later in life. Breast milk also contains less insulin (which creates fat) and keeps weight down in the early stages of life [20].

Easy to digest: for most babies, breast milk is easier to digest than formula. Babies often need time for their stomach to adjust to proteins found in cow's milk and this can cause some discomfort [20].

\subsection{CONCEPT OF EXCLUSIVE BREASFEEDING}

The importance of breastfeeding in low-income and middle-income countries is well recognized but fewer consensuses exist about its importance in high-income countries. In low-income countries and middle-income countries, only $37 \%$ of children younger than six months of age are exclusively breastfed [21]. The WHO policy of 6 months of EBF has been widely adopted by many countries.

Despite this, the majority of infants are not EBF at 6 months, particularly in developed countries. For example, on average $39 \%$ of infants in Organization for Economic Cooperation and Development countries are EBF for 4 months and $23 \%$ are EBF for 6 months. 7 The rates of EBF in the UK are even lower: in 2010, 12\% were EBF for 4 months and $1 \%$ were EBF for 6 months [22].

Exclusive breastfeeding means the infant only receives breast milk; no other solids or liquids are given not even water within the exception of oral rehydration solution or drops/syrups of vitamins, minerals or medicines [6].

\subsection{ADVANTAGES OF EXCLUSIVE BREASTFEEDING TO THE MOTHER}

The mother experiences a delay in the return of menstrual cycles

Exclusive breastfeeding can prevent the mother from getting pregnant again until she chooses to settle on weaning

Breastfeeding reduces the risk of developing breast and ovarian cancer in the mother [23].

\subsection{ADVANTAGES OF EXCLUSIVE BREASTFEEDING TO THE BABY}

An exclusively breastfed baby has a lower risk of gastrointestinal infection

It helps the baby regain all the weight lost at birth

Exclusively breastfed babies quickly recover from infection and cold.

Protects the baby from illness [23].

\subsection{DISADVANTAGES OF EXCLUSIVE BREASTFEEDING}

Www.scirj.org

(C) 2020, Scientific Research Journal

http://dx.doi.org/10.31364/SCIRJ/v8.i2.2020.P0220744 


\section{For the Mother}

The mother of the newborn baby may find it discomforting to breastfeed regularly. At the initial days of exclusive breastfeeding, the nursing mother may have sore nipples. In fact, the breastfeeding mother may find her breasts to be engorged or swollen throughout the breastfeeding period. Since exclusive breastfeeding requires the mother to feed 8-12 times in a day, it may be difficult for her to look after other household or work related chores. Considering that the only source of nutrition for the baby is the mother's milk, the latter has to compromise on her own diet. Nursing mother must be careful about her own diet and continue to avoid or limit the consumption of certain foods. Breastfeeding mothers have low libido which pushes them to compromise their sex life [23].

\section{For the Baby}

Breastfeeding is seen to be disadvantageous for the newborn baby when there is an inadequate supply of breast milk or insufficient suck reflex in the baby. If the mother does not breastfeed the baby well, the baby may experience dehydration, which can pave way for other problems. Improper breastfeeding also invites health problems such as weight loss in the baby, slow growth and development, difficulty in weaning etc. Since the nursing mother does not know how much of milk her baby needs, there is a chance the baby develops health problems due to insufficient supply of breast milk. Common signs of problems in an exclusively breastfed newborn baby includes: irritability, vomiting, crying after feeding, skin rash, diarrhea [23].

\subsection{KNOWLEDGE OF BREASTFEEDING}

A study carried out by Mbwana [24] on exclusive breastfeeding showed that more than half of pregnant women (57.5\%) knew that a baby should be breastfed on demand, only $28.8 \%$ were aware that breast milk alone is sufficient for the baby for six months while 41.3\% though 4-5 months is the appropriate age to start solid foods. About $93.8 \%$ of the women were aware that breastfeeding should continue for up two years. More than half of women (52.5\%) believed that it is right to give water to the baby after every breastfeed. Another study carried out on the knowledge, attitude and practice of exclusive breastfeeding among mothers showed that only about one third of mothers interviewed (34.7\%) mentioned up to six months for the duration of EBF [8]. One quarter of mothers knew that EBF for six months protects the child from diarrhea (27.3\%), 32\% of mothers responded that EBF could be used as contraceptive while $16.7 \%$ did not think it could be used as contraceptive [8].

Another study carried out in Kwara, Nigeria on knowledge and practice of exclusive breastfeeding [9] showed that sixty percent of the mothers were aware of EBF but only 30\% of them had the adequate knowledge of EBF having scored more than 50\% or more in the assessment of knowledge of EBF. Another study carried out by Mulugeta, Netsanet, Nigusie and Selam [25] showed that $69.8 \%$ of the respondents were grouped as having good knowledge and 30.2\% were categorized as having poor knowledge. 82\% knew about EBF 
and $18 \%$ did not know about EBF. Their major source of information was health institutions (66.4\%). $70 \%$ had good knowledge about the time to give breast milk to a child after birth.

\subsection{PRACTICE OF BREASTFEEDING}

A study carried out by Niguse, Frehiwot, Dinu and Deges [8], on the knowledge, attitude and practice of exclusive breastfeeding among mothers showed that majority of the participants $(59.9 \%)$, while only $4.5 \%$ initiated breastfeeding after one day. $66.6 \%$ of mothers were breastfeeding on demand and the majority (77.4\%) had not given any prelacteal feeds to their newborn baby, about half (47.8\%) gave plain water. EBF was reported by only $26.4 \%$ of mothers while $50.2 \%$ gave additional cow milk to their infant prior to six months of age. Another study carried out in Kwara, Nigeria on knowledge and practice of exclusive breastfeeding [9] showed that more than half $(53 \%)$ of mothers initiated breastfeeding immediately after delivery, while $47 \%$ did so long after 30 minutes. Out of the 179 mothers only $31 \%$ practiced EBF.

In a study done by Agbo et al [7], on the knowledge of breastfeeding practices among female doctors in Nigeria, all respondents knew that babies should be exclusively breastfed for the first six months of life but only 60 percent knew that breastfeeding should continue until two years.

Another study carried out in South-Eastern Nigeria on the knowledge and practice of exclusive breastfeeding [26] showed that 76.4\% of the 254 women initiated breastfeeding immediately after delivery. $63 \%$ of the women were breastfeeding exclusively at birth but the rates dropped to $30.5 \%$ at ages four to six months. Only $53.6 \%$ of the mothers practiced exclusive breastfeeding. Another study carried out by Verma and Dixit [27] on knowledge and practices of exclusive breastfeeding among women in rural Uttar Pradesh showed that of the 256 of the mothers, $70.8 \%$ did not initiate breastfeeding their babies with an hour after delivery and only $29.2 \%$ of them initiated within the hour. $67.2 \%$ gave prelacteal feeds. The practice of EBF was low among them, with only $24.8 \%$ of them going for the practice of EBF while the rest were not following it.

\subsection{CHALLENGES OF BREASFEEDING}

Mothers do not initiate breastfeeding or discontinue breastfeeding early for a variety of reasons. Some mothers stopped breastfeeding in the first month postpartum because of sore nipples, infant difficulty to latch and perceptions that they were not producing enough milk to satisfy their infants. Societal barriers to breastfeeding, such as working outside the home, length of maternity of maternity leave and embarrassment of breastfeeding in public, have been identified as factors affecting breastfeeding initiation and duration [28].

Across many rural communities in Africa where breastfeeding appears to be the norm, the question of whether to breastfeed or not, seldom arises since women are expected or required by the cultural practices of those societies to do so. Indeed, in both developed and WWW.scirj.org

(C) 2020, Scientific Research Journal

http://dx.doi.org/10.31364/SCIRJ/v8.i2.2020.P0220744 
the developing worlds, studies have showed the existence of several influences on EBF. In the developed world, women's breastfeeding decisions have been shown to be influenced by their perception of partner's attitudes and paternal involvement in breastfeeding promotion programs [5].

A study of the societal influences on infant feeding among South African mothers shows the fundamental role of social stigma, economic circumstance, maternal age, and family influences [5].

According to a study carried out by Thurman and Allen [28], lack of timely routine follow-up care and postpartum home health visits, lack of family and broad societal support, media portrayal of bottle as normative, misinformation and lack of guidance and encouragement from healthcare professionals as some of the many obstacles mothers face when attempting to initiate and continue breastfeeding. The lack of familial support, as well as lack of opportunity to observe breastfeeding in societies can make it difficult for new mothers to attempt to breastfeed. Moreover, misinformation form healthcare providers and minimal discussion about the process and benefits of breastfeeding compared with formula feeding contribute to low breastfeeding rates and increase maternal frustration and confusion regarding breastfeeding.

A study carried out on the barriers to exclusive breastfeeding among mothers in the first four weeks postpartum [29] shows that approximately half of the women (44\%) cited inadequate milk supply and sore or painful nipples (42.7\%) as barriers to continue EBF. Slightly more than one-third of the sample (34.7\%) indicated that breastfeeding was very stressful and time-consuming. The majority of women $(78.7 \%)$ noted embarrassment was not a barrier to continue EBF. In addition, $66.7 \%$ stated that return to work and return to school $(73.3 \%)$ were not barriers to continue EBF.

\subsection{ROLE OF THE MIDWIFE DURING BREASTFEEDING}

The midwife's role during the first few weeks is twofold. First she must ensure that the baby is adequately fed at the breast. Secondly her role is to support the mother in developing necessary practical positioning and attachment skills so that she is able to feed her baby independently. Whilst the baby is reflexly equipped for breastfeeding, mothers are not. All mothers, particularly those who have never experienced breastfeeding before, require encouragement and reassurance (emotional support), advice and guidance on the fundamentals of effective attachment so that feeding is pain free (practical support) and factual information about breastfeeding (informational support) in small, manageable quantities. Some mothers will need more help and support than others [18].

Many mothers who have had babies require as much support with breastfeeding as those who have given birth to their first baby. Reasons for this include:

i. Previous unsuccessful breastfeeding

WwW.scirj.org

(C) 2020, Scientific Research Journal

http://dx.doi.org/10.31364/SCIRJ/v8.i2.2020.P0220744 
ii. Breastfeeding may have gone well last time by chance rather than knowledge.

iii. They newborn baby may behave differently or have different needs from the mother's previous baby.

iv. The mother may have recently fed a toddler and has forgotten quite how much help a new baby requires to breastfeed.

v. Their previous baby may have been born at a time when underpinning information now known to be outdated was thought to be correct [18].

\subsection{THEORETICAL FRAMEWORK}

The Theory of Planned Behaviour (TPB) is one of the theoretical approaches that has been widely used by health psychologists to help understand health behaviours and to develop appropriate interventions. The principal determinant of behaviour in TPB is intentions and that intentions are determined by three main constructs: (a) attitudes, (b) subjective norms, and (c) perceived behavioural control.

TPB is influenced by three focal categories of beliefs: (a) beliefs about the outcomes of a particular behaviour, (b) beliefs about the expectations of others, and (c) beliefs about the presence of factors that might encourage or prevent a particular behaviour.

Attitude toward behaviour is determined by the individual's beliefs about outcomes or attributes of performing the behaviour (behavioural beliefs).

Subjective norm is determined by normative beliefs, and normative belief is determined by the attitude of a society in valuing and appreciating a particular behaviour of the subject.

Perceived behavioural control (PBC) is influenced by specific situational factors and is based on the factors that determine a subject's ability to perform or not perform a particular behaviour. Perceived behavioural control is affected by both intentions and behaviours. The intention to perform a desired behaviour is based on varying perceptions of individuals in performing the desired behaviour.

The theory of planned behaviour will help in understanding the reasons why certain mothers are not interested in breastfeeding, thus helping to develop appropriate promotion strategies to improve exclusive breastfeeding [29].

\subsection{APPLICATION OF THEORETICAL FRAMEWORK TO STUDY}

An infant's feeding decisions are affected by a wide range of psychological, social, clinical, cultural, and individual characteristics: factors such as age, ethnicity, educational status, and personality variables [29]. The intention of mothers to carry out exclusive breastfeeding affects the mother's behaviour. This intention is greatly influenced by the perceived outcomes of carrying out EBF to both mother and child. 
There are three determinants of intention:

Attitudes: the perceived outcome and attributes greatly affect the mother's intention. She will only carry out EBF if the benefits outweigh the risks. Previous experience can also affect the practice of EBF.

Subjective norms: The support gotten from spouse, family and friends also encourage the practice of EBF. If the mother is encouraged when she practices it and admonished when she does not, it greatly affects the practice of EBF.

Perceived behavioural control: Women who have the perception that breastfeeding is difficult to perform are less likely to breastfeed and may encourage the use of formula feeding among postpartum women. Therefore it is only women who have positive attitudes towards EBF that will be able to carry it out.

\section{CHAPTER THREE}

\subsection{RESEARCH DESIGN}

Descriptive study was used to assess knowledge, practice and challenges of breastfeeding among mothers attending antenatal clinic in Lagos University Teaching Hospital, Idi-araba

\subsection{RESEARCH SETTING}

The research was carried out at Lagos University Teaching Hospital, Idi-araba. Established in 1962, LUTH (Lagos University Teaching Hospital) as commonly referred and the Medical School Complex was enacted by a Cabinet decision made in April of 1961 following recommendations made by the Sir Eric Ashby's commission on Post-Secondary Education in Nigeria [30]. The Antenatal clinic in LUTH is an active clinic that runs from Monday to Friday of every week (excluding Wednesday) between 7am - 12pm. The clinic is located on the first floor of the outpatient department building which is the first hospital building from the Gate entry at Idiaraba. The activities of the clinic includes booking visits for new pregnant women and routine antenatal visit for booked clients.

\subsection{TARGET POPULATION}

This study was conducted among working mothers attending antenatal clinic in Lagos University Teaching Hospital, Idiaraba between 9th and 23rd August, 2019. The clinic attends to an average of 40 clients on clinic days, that is, 160 clients every week. 


\subsection{SAMPLE AND SAMPLING TECHNIQUES}

To calculate the sample size required, the Yamane's formula was used

$\mathrm{n}=\mathrm{N} /\left(1+\mathrm{N}(\mathrm{e})^{2}\right)$

Where $\mathrm{n}$ is the sample size

$\mathrm{N}$ is the number of working mothers registered to attend antenatal clinic in Lagos University Teaching Hospital, Idi-araba between 9th and 23rd August, 2019

$\mathrm{e}$ is the level of precision which is 0.05 .

$\mathrm{n}=\quad \frac{320}{(1+320(0.05)}$

$\mathrm{n}=177.78$ $\left(1+320(0.05)^{2}\right)$

A $10 \%$ allowance for unusable data and incomplete questionairres was added.

Thus, sample size $\mathrm{n}=196$

\subsection{SAMPLING TECHNIQUE}

The sampling technique that was employed for this study is simple random sampling.

\subsection{INSTRUMENT FOR DATA COLLECTION}

Data was collected using a structured questionnaires which contain the following sections:

SECTION A: Socio-demographic data/information of the respondents consisting of questions

SECTION B: The knowledge of exclusive breastfeeding

SECTION C: The practice of exclusive breastfeeding

SECTION D: The challenges of exclusive breastfeeding.

\subsection{VALIDITY OF INSTRUMENT}

The instrument was validated through review by the researcher's supervisor to ascertain face and content validity, and also to check for any unclear and ambiguous question for modification.

\subsection{ETHICAL CONSIDERATION}

The ethical clearance was obtained from the ethical committee of Lagos University Teaching Hospital through a letter of permission and presentation of research proposal. Also informed consent of participants was requested.

\subsection{METHOD OF DATA COLLECTION}

WwW.scirj.org 
Data was collected through face to face administration of the copies of the questionnaire from respondents. Data was collected by the researcher and a research assistant during the antenatal days from Friday 9th to Friday 23rd August, 2019.

\subsection{METHOD OF DATA ANALYSIS}

The data derived from the filled questionnaire was analyzed by the use of descriptive methods. A score $\geq 50 \%$ was graded as good knowledge/practice of EBF and less than was graded as poor knowledge/practice. The data was reviewed, organized and entered into a computer running the statistical package of social science (SPSS)

\section{CHAPTER FOUR}

The research was conducted among working mothers attending antenatal clinic in Lagos University Teaching Hospital, Idiaraba. 196 questionnaires were distributed and about $96 \%$ were returned and presented.

\subsection{SOCIO-DEMOGRAPHIC CHARACTERISTICS}

Table 4.1.1: Socio-demographic characteristics of respondents

\begin{tabular}{lcl}
\hline Variables & Frequency & Percentage \% \\
\hline Age (years) & 6 & 3.2 \\
$18-22$ & 23 & 12.2 \\
$23-27$ & 40 & 21.2 \\
$28-32$ & 101 & 53.4 \\
$33-37$ & 11 & 5.8 \\
$38-45$ & 8 & 4.2 \\
$43-47$ & $\mathbf{1 8 9}$ & $\mathbf{1 0 0 . 0}$ \\
Total & 6 & 3.2 \\
Marital status & 6 & \\
Single & (c) 2020, Scientific Research Journal & \\
\multicolumn{2}{c}{ http://dx.doi.org/10.31364/SCIRJ/v8.i2.2020.P0220744 } \\
\end{tabular}


Married

Divorced

Total

Religion

Christianity

Islam

Total

Educational qualification

None

Primary

Secondary

Tertiary

Total

\section{Occupation}

Civil servant

Self-employed

Unemployed

Students

Total

\section{Ethnicity}

Yoruba

Igbo

others

Total

Number of children

1

2

3

4

5 and above

Total

Income status

$<40,000 /$ month

41000 - 70000

71000-100000

Total
179

4

189

130

59

189

10

23

38

189

22

113

36

18

189

111

44

34

189

33

62

58

18

18

189

73

94

22

189
94.7

100.0

68.8

31.2

100.0

5.3

12.2

118

62.4

2.1
20.1

100.0

11.6

59.8

19.0

9.5

100.0

58.7

23.3

18.0

100.0

17.5

32.8

30.7

9.5

9.5

100.0

38.6

49.7

11.6

100.0

Table 4.1.1 shows that more than half of the respondents $53.4 \%$ are within the age range 33-37 years and a strong majority of the respondents $94.7 \%$ were married. Majority of the respondents $68.8 \%$ practice Christianity. Majority of the respondents, $62.4 \%$ had the secondary level of educational qualification. More than half $59.8 \%$ were self employed and $49.7 \%$ had an average income status.

\subsection{KNOWLEDGE OF EXCLUSIVE BREASTFEEDING}

Table 4.2.1: Knowledge of respondents on exclusive breastfeeding.

\begin{tabular}{lll}
\hline Variables & Frequency & Percentage \% \\
\hline Have you heard about exclusive breastfeeding before? & 189 & 100.0 \\
Yes & 0 & 0 \\
No & $\mathbf{1 8 9}$ & $\mathbf{1 0 0 . 0}$ \\
Total & 189 & 100.0 \\
Were you at any time educated on exclusive breastfeeding? & 0 \\
Yes & 0 & $\mathbf{1 0 0 . 0}$ \\
No & $\mathbf{1 8 9}$ & $\mathbf{5 . 3}$
\end{tabular}


Newspaper

Hospital

Friends/relations

Total

How long should your baby be exclusively breastfed for? 6months

1year

3months

I don't know

Total

\section{4}

119

56

118

26

41

4

189

189
2.1

63.0

29.6

100.0

62.4

21.7

13.8

2.1

100.0

Table 4.2.1 shows that all the respondents have heard about exclusive breastfeeding and that they have been educated on exclusive breastfeeding. The source of information on exclusive breastfeeding was majorly the hospital, 63\%. Also, a greater promotion of women, $62.4 \%$ expressed that babies should be exclusively breastfed for 6 months.

Table 4.2.2: Knowledge of respondents on exclusive breastfeeding.

\begin{tabular}{|l|l|l|l|}
\hline \multicolumn{1}{|c|}{ QUESTION } & YES (\%) & NO (\%) & $\begin{array}{c}\text { I DON'T } \\
\text { KNOW (\%) }\end{array}$ \\
\hline Breastfeeding should be continued for up to 2 years of life & $81(42.9)$ & $87(46.0)$ & $21(11.1)$ \\
\hline $\begin{array}{l}\text { You are allowed to give your baby vitamins and supplements } \\
\text { while breastfeeding your baby }\end{array}$ & $64(33.9)$ & $103(54.5)$ & $22(11.6)$ \\
\hline $\begin{array}{l}\text { Giving water is encouraged to the baby after every } \\
\text { breastfeeding }\end{array}$ & $21(11.1)$ & $157(83.1)$ & $11(5.8)$ \\
\hline $\begin{array}{l}\text { Supplementing breast milk with formula during the first week } \\
\text { of life is good }\end{array}$ & $49(25.9)$ & $108(57.1)$ & $32(16.9)$ \\
\hline $\begin{array}{l}\text { Exclusive breastfeeding can be used as a family planning } \\
\text { method }\end{array}$ & $75(39.7)$ & $90(47.6)$ & $24(12.7)$ \\
\hline
\end{tabular}




\begin{tabular}{|l|l|l|l|}
\hline $\begin{array}{l}\text { A woman who is exclusively breastfeeding is less likely to get } \\
\text { pregnant }\end{array}$ & $92(48.7)$ & $66(34.9)$ & $31(16.4)$ \\
\hline Exclusive breastfeeding helps in weight loss & $87(46.0)$ & $62(32.8)$ & $40(21.2)$ \\
\hline Complementary feeds can be introduced after 6 months of life & $167(88.4)$ & $18(9.5)$ & $4(2.1)$ \\
\hline $\begin{array}{l}\text { Exclusive breastfeeding helps in protecting the baby from } \\
\text { illness and allergies }\end{array}$ & $168(88.9)$ & $10(5.3)$ & $11(5.8)$ \\
\hline
\end{tabular}

Table 4.2.2 shows that only $42.9 \%$ of the respondents agreed that breastfeeding should be continued for up to 2 years of life. Majority of the respondents $(83.1 \%)$ said giving water after breastfeeding should not be encouraged. $57.1 \%$ of the respondents said supplementing breast milk with formula during the first week of life is not good. Majority of respondents $88.9 \%$ said exclusive breastfeeding helps in protecting the baby from illness and allergies. 


\section{Figure 4.2.1. Overall Knowledge of Exclusive Breastfeeding}

Figure 4.2.1 shows that majority of the respondents (62.4\%) had good knowledge of exclusive breastfeeding while the rest $(37.6 \%)$ had poor knowledge of exclusive breastfeeding.

\subsection{PRACTICE Of EXCLUSIVE BREASTFEEDING}

Table 4.3.1: Practice of exclusive breastfeeding among respondents

\begin{tabular}{|c|c|c|c|c|}
\hline Variables & & Frequency & & Percentage \% \\
\hline \multicolumn{5}{|c|}{ How often should a baby breastfeed? } \\
\hline On demand & & 117 & & 61.9 \\
\hline By routine & & 48 & & 25.4 \\
\hline Dont know & & 24 & & 12.7 \\
\hline Total & & 189 & & 100.0 \\
\hline \multicolumn{5}{|c|}{ How often does your baby breastfeed? } \\
\hline 5-6times/day & & 6 & & 3.2 \\
\hline 7-8times/day & & 83 & & 43.9 \\
\hline 8times/day & & 69 & & 36.5 \\
\hline More than 8 times/day & & 31 & & 16.4 \\
\hline Total & & 189 & & 100.0 \\
\hline \multicolumn{5}{|c|}{ How soon after delivery did your baby breastfeed? } \\
\hline Immediately & & 120 & & 63.5 \\
\hline Before the end of the day & 59 & & 31.2 & \\
\hline After 24 hours & & 10 & & 5.3 \\
\hline Total & & 189 & & 100.0 \\
\hline \multicolumn{5}{|c|}{$\begin{array}{l}\text { Do you intend to give your baby formula milk in } \\
\text { the first six months of life }\end{array}$} \\
\hline Yes & & 75 & & 39.7 \\
\hline No & & 114 & & 60.3 \\
\hline Total & & 189 & & 100.0 \\
\hline \multicolumn{5}{|c|}{ Do you give your baby any artificial food? } \\
\hline Yes & & 117 & & 61.9 \\
\hline No & & 72 & & 38.1 \\
\hline Total & & 189 & & 100.0 \\
\hline \multicolumn{5}{|c|}{ If your answer is yes, which type of artificial food } \\
\hline Pap & & 23 & & 19.7 \\
\hline Water & & 47 & & 40.2 \\
\hline Custard & 20 & & 17.1 & \\
\hline Goldenmrn & & 14 & & 12.0 \\
\hline fiso gold & 13 & & 11.1 & \\
\hline Total & & 117 & & 100.0 \\
\hline
\end{tabular}


Table 4.3.1 shows that majority of the respondents (61.9\%) reported that they breastfed their baby on demand. Most of the respondents $(63.5 \%)$ said they breast fed their babies immediately after delivery. Majority of the respondents $(60.3 \%)$ indicated that they don't intend to give their baby formula milk in the first six months of life. Majority of the respondents $117(61.9 \%)$ indicated that they give their babies artificial food.

Table 4.3.2: Practice of exclusive breastfeeding among respondents

\begin{tabular}{|c|c|c|}
\hline Variables & Frequency & Percentage $\%$ \\
\hline $\begin{array}{l}\text { Breastfeeding should be con } \\
\text { even though the baby has re }\end{array}$ & & \\
\hline True & 142 & 75.1 \\
\hline False & 28 & 14.8 \\
\hline Dont know & 19 & 10.1 \\
\hline Total & 189 & 100.0 \\
\hline Do you give your baby wate & & \\
\hline Yes & 62 & 32.8 \\
\hline No & 127 & 67.2 \\
\hline Total & 189 & 100.0 \\
\hline Do you give your baby prela & & \\
\hline Yes & 24 & 12.7 \\
\hline No & 165 & 87.3 \\
\hline Total & 189 & 100.0 \\
\hline If your answer is yes, state tl & & \\
\hline Water & 16 & 66.7 \\
\hline Grape water & 8 & 33.3 \\
\hline Total & 24 & 100.0 \\
\hline $\begin{array}{l}\text { Have you tried exclusive bre } \\
\text { planning method before? }\end{array}$ & & \\
\hline Yes & 70 & 37.0 \\
\hline No & 119 & 63.0 \\
\hline Total & 189 & 100.0 \\
\hline What position do you assum & by? & \\
\hline Side lying & 16 & 8.5 \\
\hline Sitting on a mat & 30 & 15.9 \\
\hline Sitting on the edge of the bed & 58 & 30.7 \\
\hline Sitting on a chair & 85 & 45.0 \\
\hline Total & 189 & 100.0 \\
\hline How does your baby latch? & & \\
\hline Breast to baby & 17 & 9.0 \\
\hline Baby to breast & 41 & 21.7 \\
\hline Both & 123 & 65.1 \\
\hline Don't know & 8 & 4.2 \\
\hline Total & 189 & 100.0 \\
\hline
\end{tabular}

Table 4.3.1 shows that majority of the respondents $(75.1 \%)$ agreed that Breastfeeding should be continued up to 2 years of life even though the baby has received solid food and most of the respondents $(67.2 \%)$ do not give their babies water after breastfeeding. 
Figure 4.2: Overall Practice of Breastfeeding

Figure 4.2 shows that more than average of the respondents (59.8\%) have good practice of exclusive breastfeeding.

\subsection{CHALLENGES OF EXCLUSIVE BREASTFEEDING}

Table 4.4.1: Challenges of exclusive breastfeeding among respondents

\begin{tabular}{|l|c|c|c|c|}
\hline \multicolumn{1}{|c|}{ Items } & $\begin{array}{c}\text { Very } \\
\text { challenging } \\
(\%)\end{array}$ & $\begin{array}{c}\text { Challenging } \\
(\%)\end{array}$ & $\begin{array}{c}\text { Not } \\
\text { challenging } \\
(\%)\end{array}$ & $\begin{array}{c}\text { No sure } \\
(\%)\end{array}$ \\
\hline Husband does not support breastfeeding & 0 & $38(20.1)$ & $123(65.1)$ & $28(14.8)$ \\
\hline Cracked, sore nipples & $74(39.2)$ & $70(37.0)$ & $42(22.2)$ & $3(1.6)$ \\
\hline Health condition of the mother & $111(58.7)$ & $62(32.8)$ & $16(8.5)$ & 0 \\
\hline Health condition of the baby & $99(52.4)$ & $64(33.9)$ & $12(6.3)$ & $14(7.4)$ \\
\hline Work schedule & $57(30.2)$ & $55(29.1)$ & $50(26.5)$ & $27(14.3)$ \\
\hline Number of children & $10(5.3)$ & $16(8.5)$ & $131(69.3)$ & $32(16.9)$ \\
\hline $\begin{array}{l}\text { Maternity leave of 3 months is not long } \\
\text { enough for successful breastfeeding }\end{array}$ & $20(10.6)$ & $31(16.4)$ & $125(66.1)$ & $13(6.9)$ \\
\hline Selected places to breastfeed at the workplace & $34(18.0)$ & $57(30.2)$ & $84(44.4)$ & $14(7.4)$ \\
\hline Feeling shy of breastfeeding in public & & & & \\
\hline Sociocultural pressure & $3(1.6)$ & $16(8.5)$ & $150(79.4)$ & $20(10.6)$ \\
\hline Inather's perception & $8(4.2)$ & $64(33.9)$ & $99(52.4)$ & $18(9.5)$ \\
\hline & $68(36.0)$ & $74(39.2)$ & $41(21.7)$ & $6(3.2)$ \\
\hline & & & & \\
\hline
\end{tabular}

Table 4.4 shows that the most challenging factors of exclusive breastfeeding identify in this study were: health condition of the mother $(58.7 \%)$, health condition of the baby (52.4\%), cracked or sore nipples (39.2\%), inadequate production of milk (36.9\%) and work schedule (30.2\%). 
Table 4.5: Relationship between the respondents' knowledge of exclusive breastfeeding and its practice.

\begin{tabular}{|c|c|c|c|c|c|c|}
\hline \multirow[t]{2}{*}{ Overall practice } & \multicolumn{2}{|c|}{ Overall knowledge } & \multirow[t]{2}{*}{ Total } & \multirow[t]{2}{*}{$\mathrm{X}^{2}$} & \multirow[t]{2}{*}{$\mathrm{df}$} & \multirow[t]{2}{*}{ P-value } \\
\hline & Good & Poor & & & & \\
\hline Good & $64(56.6)$ & $49(43.4 \%)$ & $113(100.0 \%)$ & 4.026 & 1 & 0.045 \\
\hline Poor & $54(71.1 \%)$ & $22(28.9 \%)$ & $76(100.0 \%)$ & & & \\
\hline Total & $118(62.4 \%)$ & $71(37.6 \%)$ & $189(100.0)$ & & & \\
\hline
\end{tabular}

Table 4.5 shows that there is a significant association between the knowledge of exclusive breastfeeding and its practice among working mothers attending antenatal clinic in Lagos University Teaching Hospital $\left(\mathrm{X}^{2}=4.026, \mathrm{p}=0.045\right)$.

Table 4.6: Relationship between the practice of exclusive breastfeeding and educational qualification of the respondents.

\begin{tabular}{|c|c|c|c|c|c|c|}
\hline \multirow[b]{2}{*}{ Variables } & \multicolumn{2}{|c|}{ PRACTICE } & \multirow[b]{2}{*}{ Total $(\%)$} & \multirow[b]{2}{*}{$\mathbf{X}^{2}$} & \multirow[b]{2}{*}{ df } & \multirow[b]{2}{*}{ p-value } \\
\hline & $\operatorname{Good}(\%)$ & Poor (\%) & & & & \\
\hline \multicolumn{7}{|c|}{ Educational qualification } \\
\hline None & $9(90.0)$ & $1(10.0)$ & $10(100.0)$ & 7.894 & 3 & 0.048 \\
\hline Primary 17 & $6(26.1)$ & $23(100.0)$ & & & & \\
\hline Secondary & \multicolumn{3}{|c|}{$63(53.4) 55(46.6) 118(100.0)$} & & & \\
\hline \multicolumn{7}{|c|}{ Tertiary $24(63.2) 14(36.8) 38(100.0)$} \\
\hline Total & $113(59.8)$ & \multicolumn{2}{|c|}{$76(40.2) 189(100.0)$} & & & \\
\hline
\end{tabular}

From the table above, there is a significant association between the practice of exclusive breastfeeding and educational qualification of working mothers attending antenatal clinic in Lagos University Teaching Hospital $\left(X^{2}=7.894, p=0.048\right)$.

\section{CHAPTER FIVE}

\subsection{DISCUSSION}


The result of this study showed that more than half of the respondents are within the age range 33-37years and a strong majority of the respondents were married. Most of the respondents practice Christianity. Majority of the respondents' educational qualification is secondary school. More than half of the respondents are from Yoruba ethnic group. Majority of the respondents 59.8\% were self employed and $49.7 \%$ had an average income status. This result is similar to the result of the study conducted by Akinyinka, Olatona and Oluwole [31] on Breastfeeding Knowledge and Practices among Mothers of Children under 2 Years of Age Living in a Military Barrack in Southwest Nigeria which revealed that majority of the respondents were married but the result differ in terms of tribe in that a larger proportion of them were Hausas.

The result also expressed that majority of the respondents have good knowledge on exclusive breastfeeding, this agrees with another study carried out by Mulugeta, Netsanet, Nigusie and Selam [25] which revealed that $69.8 \%$ of the respondents were grouped as having good knowledge and 30.2\% were categorized as having poor knowledge on breast feeding. The result from this current study revealed that majority of the respondents said babies should be exclusively breastfed for 6months. This is consistent with another study carried out on exclusive breastfeeding among city-dwelling professional working mothers in Ghana by Dun-Dery and Laar [32] which showed that majority of the respondents knew that a child should be breastfed for the first six months. The result of this current study is also consistent with a study done in Nigeria on the knowledge of breastfeeding practice among female doctors in Nigeria; all respondents knew that babies should be exclusively breastfed for the first six months of life but only majority knew that breastfeeding should continue until two years [7].

All the respondents had heard about exclusive breastfeeding and that they have been educated on exclusive breastfeeding. Most of the respondents' source of information is the hospital. This finding is similar to a study carried out by Mulugeta, Netsanet, Nigusie and Selam [25] which reported that the major source of information of majority of the women was health institutions.

The findings from this study showed that majority of the respondents have good practice of exclusive breastfeeding. This is consistent with a study carried out by Onah, Osuorah and Ndukwu [33] which also revealed that the practice of EBF is fair. Meanwhile, the result from this current study disagree with a study carried out by Agbo et al.[7], which revealed that the practice of EBF was done by only minority of the women. In another study done in Ethiopia on the breastfeeding practice among nurses and midwives, the exclusive breastfeeding rate was found to be less than and nearly half of the respondents exclusively breastfed for only 3 months or less [34]. The findings from this study revealed that less than of the respondents gave water to their babies after breast feeding. This is dissimilar with a study carried out by Mbwana [24] where more than half of women believed that it is right to give water to the baby after every breastfeed. 
The findings from this study revealed that most of the respondents reported that they breast fed their babies immediately after delivery. This is similar to another study carried out in South-Eastern Nigeria on the knowledge and practice of exclusive breastfeeding which showed that women initiated breastfeeding immediately after delivery [26].

The result elicited that the most challenges of exclusive breastfeeding identify in this study were: health condition of the mother, health condition of the baby, cracked or sore nipples, inadequate production of milk and work schedule. This findings is similar to a study carried out on the barriers to exclusive breastfeeding among mothers in the first four weeks postpartum by Thomas [29] shows that approximately half of the women cited inadequate milk supply and sore or painful nipples as barriers to continue EBF. Slightly more than one-third of the sample indicated that breastfeeding was very stressful and time-consuming. Meanwhile another study carried out by Onah, Osuorah and Ndukwu [33] identify some other factors such as low maternal education, higher socioeconomic status, non-vaginal birth and use of prelacteal feeds were significant predictors of lower EBF practices.

\subsubsection{Research hypotheses}

The findings from this study revealed that there is a significant association between the knowledge of exclusive breastfeeding and its practice among working mothers attending antenatal clinic in Lagos University Teaching Hospital. Therefore the null hypothesis will be rejected. This agrees with the findings of Agu and Agu [26] which states that Practice of exclusive breast feeding was not commensurate with mothers' knowledge of exclusive breastfeeding that is there is a significant association between respondents' knowledge and practice of exclusive breastfeeding.

The findings also showed that there is a significant association between practice of exclusive breastfeeding and educational qualification of respondents. This findings was in contrast with the outcome of Oche, Umar and Ahmed [9] which revealed that education of the respondents had no influence on the practice of exclusive breastfeeding (EBF) as there was no statistically significant difference between those with formal education and informal education with regards to the practice of $E B F(p=0.986$ ).

\subsection{IMPLICATION TO NURSING}

Nurses/midwives are saddled with the task to ensure mothers attending Antenatal clinic as well as the public are knowledgeable about proper way of breastfeeding. Nurses/Midwives having knowledge of Exclusive Breast Feeding should teach women the importance of exclusive breastfeeding to both mothers and baby, as this will help inform mothers and the community at large on the effect the practice of non-exclusive breastfeeding will have on both mother and baby which will improve the overall practice of exclusive breastfeeding and also improve the child's well-being. Nurses and midwives in various health care facilities are to partake in the formulation of policies that will enhance the practice of exclusive breastfeeding. 


\subsection{SUMMARY}

The purpose of this study was to assess the knowledge, practices and challenges of exclusive breastfeeding among working mothers attending antenatal clinic in Lagos University Teaching Hospital, Idiaraba. The researcher conducted an extensive literature review to gain information on previous related studies done in order to get an in-depth understanding of the topic. The researcher used a structured questionnaire to collect data, which was analyzed and revealed that the knowledge of exclusive breastfeeding was $62.4 \%$, the practice of exclusive breastfeeding was 59.8\%. Some of the challenges of exclusive breastfeeding identified were: health condition of the baby, health condition of the mother, cracked or sore nipples, inadequate production of milk and work schedule.

\subsection{CONCLUSION}

This study has shown that the women have good knowledge and practice of exclusive breastfeeding as well as good practice of breastfeeding. The most challenging factors of breastfeeding identify in this study were condition of the mother, health condition of the baby, cracked or sore nipples, inadequate production of milk and work schedule. The study also shows that there is a significant relationship between the respondents' knowledge of exclusive breastfeeding and its practice. Also, there is a significant relationship between respondents' practice of breastfeeding and their educational qualification.

\subsection{RECOMMENDATIONS}

Based on the findings of this study the following were recommended:

i. The government should formulate policies that will be generally accepted by the public on exclusive breastfeeding.

ii. The community and the government should work together to ensure that every girl-child is educated, and guarantee that workplace is free of harassment and discrimination against women who prefer to breastfeed their babies through appropriate mechanisms.

iii. Health sector should mandate that proper health education is carried out in hospitals for pregnant women receiving antenatal care in their facilities.

iv. The midwife should ensure the mother and the baby are prevented or treated for any disease that may hinder breastfeeding

v. Professional working mothers must initiate and arrange childcare for the infants close to the mother's work place to enable their babies to be brought to the workplace or breastfeeding mothers to go to the child care facility at breastfeeding period.

vi. This study demonstrates the need to educate women on early treatment of any post-partum morbidity in order to ensure proper EBF practices.

\subsection{SUGGESTIONS FOR FURTHER STUDIES}


Further studies should be conducted with a larger sample and in a different geographical region in order to ascertain the findings of this study. Further studies should also explore policies ensuring and guaranteeing breaks from work for working mothers to breastfeed babies particularly during the time frame for exclusive breastfeeding.

\section{REFERENCES}

[1] Awano M. and Shimada K., "Development and evaluation of a self care program on breastfeeding in Japan: A quasi-experimental study," International Breastfeeding Journal, vol. 5, no. 1, p. 9, 2010.

[2] Pound C.M. and Unger S.L., "The Baby-Friendly Initiative: Protecting, promoting and supporting breastfeeding,” Paediatrics \& Child Health, vol. 17, no. 6, pp. 317-321, 2012.

[3] Okafor I.P., Olatona F.A., and Olufemi O.A., "Breastfeeding practices of mothers of young children in Lagos, Nigeria," Nigerian Journal of Paediatrics, vol. 41, no. 1, pp. 43-47, 2014.

[4] WHO/UNICEF, “Innocenti Declaration 2005: On Infant and Young Child Feeding. "Celebrating Innocenti 1990-2005: Achievements, Challenges and Future Imperatives,"," Florence, Italy, 2005, http://innocenti15.net/declaration.pdf.pdf.

[5] Seidu I., Exclusive breastfeeding and family influences in rural Ghana: A qualitative study. Retrieved May 15, 2018

[6] WHO (2015). World Health Organisation. Retrieved July 29, 2015, from Exclusive Breastfeeding: http://www.who.int/elena/titles/exclusive_breastfeeding/en/

[7] Agbo H.A, Envuladu E.A, Adams H.S., Inalegwu E., Oko E. and Zookah A. (2013). Barriers and facilitators to the practice of exclusive breastfeeding among working class mothers: A study of female resident doctors in tertiary health institutions in Plateau state. Journal of Medical Research, 2(1), 0112-0116. Retrieved September 12, 2015

[8] Niguse T., Frehiwot H., Dinu A. \& Eyerus D (2016). Knowledge, attitude and practice towards exclusive breastfeeding among lactating mothers in Mizan Aman town, Southwestern Ethiopia: descriptive cross-sectional study. International Breastfeeding Journal, 11(3). Retrieved May 20, 2018

[9] Oche M.O., Umar A.S. and Ahmed H., "Knowledge and practice of exclusive breastfeeding in Kware, Nigeria". Makerere Medical School, Uganda. African Health Sciences. Retrieved May 30, 2018

[10] Alison, S., “The risk of not breastfeeding for mothers and infants”. Reviews in Obstetrics and Gyneacology , (2009) 4, $222-231$.

[11] Danso, J., "Examining the practice of exclusive breastfeeding among professional working motere in Kumasi Metropolis of Ghana”. International Journal of Nursing , 1, 1-5. (2014)

[12] American Pregnancy Association, Retrieved September 20, 2015, from What's in Breast Milk?: http://americanpregnancy.org?first-year-of-life?whats-in-breastmilk/

[13] New Port Hospital, “Types of breast milk”. Retrieved September 20, 2015, from http://www.newporthospital.or/services/noreenstonor-drexel-birthing-center/breastfeeding-basics/types-of-breast-milk.html 
[14] Rasmuseen K.M., Felice J.P. O'Sullivan E.J. Garner C.D. and Geraghty S.R. (2017). The meaning of breastfeeding is changing and so must our language about it. Breastfeeding Medicine, 12(9), 510-514. Retrieved January 31, 2018

[15] Stoppler M.C. (2017). Breastfeeding and formula feeding. Retrieved May 21, 2018, from MedicineNet: https://www.medicinenet.com/breastfeeding/article.html

[16] American Academy of Pediatrics, "Breastfeeding and the Use of Human Milk” Pediatrics December 1997, 100 (6) 1035-1039; DOI: https://doi.org/10.1542/peds.100.6.1035

[17] Caesar G.V., Association between breastfeeding and intelligence, educational attainment, and income at 30 years of age: a prospectiv birth chort study from Brazil. Science Direct, 3(4), e199-e205. (2015). Retrieved January 31, 2018

[18] Marshall J. \&Raynor M., “Myles Texbook For Midwives” (Vol. 16). (2014) Elsevier. Retrieved June 3, 2018

[19] Bjarnadottir A., "11 Benefits of breastfeeding for both mom and baby” (2017).Retrieved September 25, 2015.

[20] CBHS Health Fund Blog, "The advantages of breastfeeding”. Retrieved May 21, 2018, from http://www.cbhs.com.au/healthwell-being-blo/blog-article/2014/11/24/the-advantages-of-breastfeeding

[21] Caesar G.V. (2016). Breasfeeding in the 21st Century: epidemiology, mechanisms and lifelong effects. 387(10017), 475-490.

Retrieved January 31, 2018

[22] Quigley M.A., Carson C. Sacker A. and Kelly Y,. Exclusive breastfeeding duration and infant infection. European Journal of Clinical Nutrition, 70(12), 1420-1427. Retrieved September 20, 2015

[23] Bhadra K. (2012). Advantages and Disadvantages of Exclusive Breastfeeding. Retrieved September 25, 2015, from UNICEF Neonatal Care: http://www.babycare.onlymyhealth.com?advantages-disadvantages-exclusive-breastfeeding-1338206371

[24] Mbwana H.A. (2012). Exclusive breastfeeding: Mothers' awareness and healthcare providers practices during antenatal visits in Mvomero, Tanzania. Retrieved May 20, 2018

[25] Mulugeta W.A.,Netsanet H.B., Nigusie B.T. and Selam F.K., Knowledge and attitude towards exclusive breast feeding among mothers attending antenatal and immunization clinic at Dabat health center, Northwest Ethipia: A cross sectional institution based study. Nursing Research and Practice, 2017. Retrieved May 30, 2018

[26] Agu M. and Agu M.C. (2011). Knowledge and practice of exclusive breastfeeding among mothers in a rural population in Southeastern Nigeria. Tropical Journal of Medical Research, 15(2). Retrieved June 1, 2018

[27] Verma A. and Dixit P. (2016). Knowledge and practices of exclusive breastfeeding among women in rural Uttar Pradesh. Journal of Neonatal Biology, 5(228). Retrieved May 30, 2018

[28] Thurman S.E. and Allen P.J. (2015.). Integrating lactation consultants into primaryhealth care services: are lactation consultanst affecting breastfeeding success? 34(5), 419-425. Retrieved May 20, 2018 
[29] Thomas J.V., "Barriers to exclusive breastfeeding among mothers during the first four weeks postpartum". (2016). Retrieved May 20, 2018

[30] Lagos University Teaching Hospital, LUTH: An Historical Perspective. (2016) www.luth.org.ng/show/history

[31] Akinyinka M.R., Olatona F.A., and Oluwole E.O., "Breastfeeding Knowledge and Practices among Mothers of Children under 2 Years of Age Living in a Military Barrack in Southwest Nigeria". International Journal of Maternal and Child Health and AIDS 2016; 5(1): $1-13$.

[32] Dun-Dery E.J., and Laar A.K., "Exclusive breastfeeding among city-dwelling professional working mothers in Ghana". International Breastfeeding Journal 11, 23 (2016)

[33] Onah S., Osuorah D.I.C., and Ndukwu I., "Infant feeding practices and maternal socio-demographic factors that influence practice of exclusive breastfeeding among mothers in Nnewi South-East Nigeria: a cross-sectional and analytical study". International Breastfeeding Journal 9, 6 (2014)

[34] Dachew B.A., and Bifftu B.B., "Breastfeeding practice and associated factors among female nurses and midwives at North Gondar Zone, Northwest Ethiopia: a cross-sectional institution based study”. International Breastfeeding Journal 9, 11 (2014) 